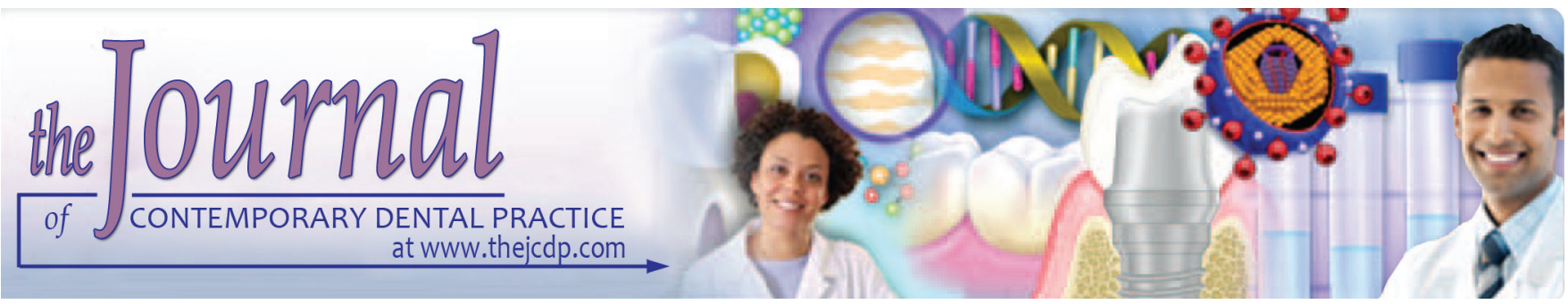

\title{
Intricate Assessment and Evaluation of Long-term Implant Success as affected by Clinicomicrobial and Salivary Diagnostics in Type II Diabetic Patients: A Longitudinal Study
}

\author{
${ }^{1}$ Deepti Raghav, ${ }^{2}$ Fawaz Alqahtani, ${ }^{3}$ Fatima J Albaker, ${ }^{4}$ Tushar V Bhagat, ${ }^{5}$ Zaheer Kola
}

\begin{abstract}
Introduction: Replacement of missing teeth by dental implants is one of the most common methods employed these days. Because of significant advancement in the design of implants and modifications in the procedure of dental implant surgery, the survival rate of the dental implants has reached up to approximately $95 \%$. Osseointegration is one of the important factors affecting the survival of dental implants. Apart from these, the body's physiologic alterations can also predispose the dental implants for failure. Diabetes is one such metabolic disease characterized by abnormal or delayed wound healing. Hence, we assessed the clinicomicrobial and salivary profile of diabetic patients undergoing rehabilitation by dental implants.
\end{abstract}

Materials and methods: This study included diabetic patients who underwent dental implant surgeries for prosthetic rehabilitation. Follow-up records of the patients' up to 1 year were maintained. Various clinicoradiographic and periodontal parameters were measured at various time intervals during follow-up time; $25 \mathrm{~mL}$ of salivary and blood sample was taken from all the subjects and was sent to the laboratories for assessment of various salivary biomarkers. All the results were analyzed by Statistical Package for the Social Sciences software.

Results: The mean level of interleukin- $\beta$ at baseline time was found to be 2.38 and 2.21 in diabetic group and control group

\footnotetext{
${ }^{1}$ Department of Prosthodontics, Shree Bankey Bihari Dental College \& Research Centre, Ghaziabad, Uttar Pradesh, India

${ }^{2,4,5}$ Department of Prosthetic Dental Sciences, College of Dentistry, Prince Sattam Bin Abdulaziz University, Alkharj Kingdom of Saudi Arabia

${ }^{3}$ Department of Prosthodontics, Hamad Medical Corporation Doha, Qatar

Corresponding Author: Deepti Raghav, Department of Prosthodontics, Shree Bankey Bihari Dental College \& Research Centre, Ghaziabad, Uttar Pradesh, India, Phone: +919990988317, e-mail: dhirk160@gmail.com
}

respectively. While comparing the levels of osteoprotegerin in both study groups, a significant correlation was obtained. In diabetic and control group, 62 and 61 years was the mean age of the patients respectively. No significant correlation was obtained while comparing the microbial flora of diabetic and control group.

Conclusion: In both diabetic and nondiabetic patients, similar microbial, salivary marker, and clinicoradiological patterns were seen.

Clinical significance: Diabetic patients who maintain their body's metabolic rate show similar success rate of dental implants as seen in nondiabetic patients.

Keywords: Diabetes, Implant, Interleukin.

How to cite this article: Raghav D, Alqahtani F, Albaker FJ, Bhagat TV, Kola Z. Intricate Assessment and Evaluation of Long-term Implant Success as affected by Clinicomicrobial and Salivary Diagnostics in Type II Diabetic Patients: A Longitudinal Study. J Contemp Dent Pract 2017;18(5):405-409.

Source of Support: Nil

Conflict of Interest: None

\section{INTRODUCTION}

One of the most common methods employed these days for the restoration of missing teeth is by dental implants. A significant advancement in the design of implants and modifications in the procedure of dental implant surgery have led the surgeons in reaching the success rate of dental implants to approximately $95 \% .{ }^{1}$ One of the most important factors for full successful placement of dental implants is osseointegration. Any defect in osseointegration can lead to failure of dental implant. Success of dental implants also depends on a number of body's metabolic factors. One such factor or condition affecting the success of dental implants is the diabetes. Diabetes mellitus is a chronic disease leading to the state of hyperglycemia 
and further complications involving multiple organs and tissues, including the interruption in the physiological process of wound healing. ${ }^{2,3}$ Hence, we assessed the clinicomicrobial and salivary profile of diabetic patients undergoing rehabilitation by dental implants.

\section{MATERIALS AND METHODS}

This study was conducted in the oral implantology section of the institution and included all diabetic patients who underwent dental implant surgeries for prosthetic rehabilitation. Ethical approval was taken from the Institutional Ethical Committee and written consent was obtained from the patients enrolled in the study after explaining to them the entire research protocol. Patients with age below 20 years or above 45 years, with a history of any other systemic illness apart from diabetes, affected by any blood disorders, any history of previous major or minor surgical procedure in the same region, or any known drug allergy were excluded from this study. The patients with any acute infectious or inflammatory conditions were also excluded from this study. Other groups of patients who recovered dental implants and with same selection and exclusion criteria but with the absence of diabetes were also assessed as control groups. Only those patients were included in whom follow-up record of a minimum of 1 year could be maintained. Complete intraoral clinical examination of the patients was done. Measuring of periodontal probing depth (PPD), the level of free gingival margin, attachment level (AL) clinically, and bleeding elicited on probing (BP) of the tooth and the implant sites was done. Plaque index was also calculated following the criteria of Haffajee et al. ${ }^{4}$ Follow-up examination was done at baseline and at various time intervals up to 1 year. Intraoral periapical radiographs were taken for assessment of radiographic changes. Mesial and distal surfaces of both the tooth and

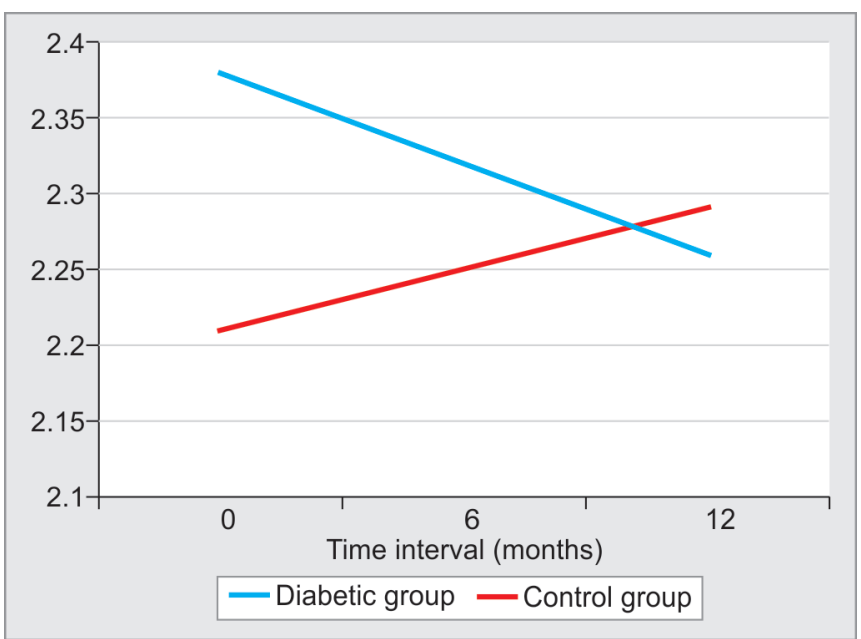

Graph 1: Mean levels of IL- $\beta$ ( $\log 10 \mathrm{pg} / \mathrm{mL}$ ) during follow-up time the dental implant were taken as standard for measurement of the linear bone levels. Cementoenamel junction, restoration of apicalmost borders and junction of crown to the abutment in cases of dental implants were used as standard points for measuring height of the alveolar bone at different follow-up time intervals. At the screening time, baseline, and 1 year follow-up time, $25 \mathrm{~mL}$ of salivary sample was taken from all the subjects and was sent to the laboratories for the assessment of the following biomarkers: Interleukins, matrix metalloproteinase, and osteoprotegerin (OP). Sandwich enzyme-linked immunosorbent assay was used for evolution of protein biomarkers. Mesial surfaces of implants and nearby teeth were used to extract the plaque biofilms at subgingival levels at various follow-up time intervals. Biofilm was harvested with the use of a sterile Gracey curette. All the samples were sent to the laboratory for microbial growth assessment. Quantitative polymerase chain reaction was used to detect various components of microbial flora as described by Mullally et al. ${ }^{5}$ Statistical Package for the Social Sciences software was used for the assessment of all the results. Chi-square test, paired t test, and one-way analysis of variance were used for assessing the level of significance; $\mathrm{p}<0.05$ was taken as significant.

\section{RESULTS}

Graph 1 shows the mean levels of IL- $\beta$ during follow-up time. At baseline time, the mean level of IL- $\beta$ was found to be 2.38 and 2.21 in diabetic group and control group respectively. At 6 months follow-up time, the mean value of IL- $\beta$ was found to be 2.32 and 2.23 in diabetic and control group respectively. Graph 2 highlights the mean levels of OP (log $10 \mathrm{pg} / \mathrm{mL})$ during follow-up time. Significant correlation was observed in the levels of OP between the diabetic group and control group. Graph 3 shows the demographic details of the patients.

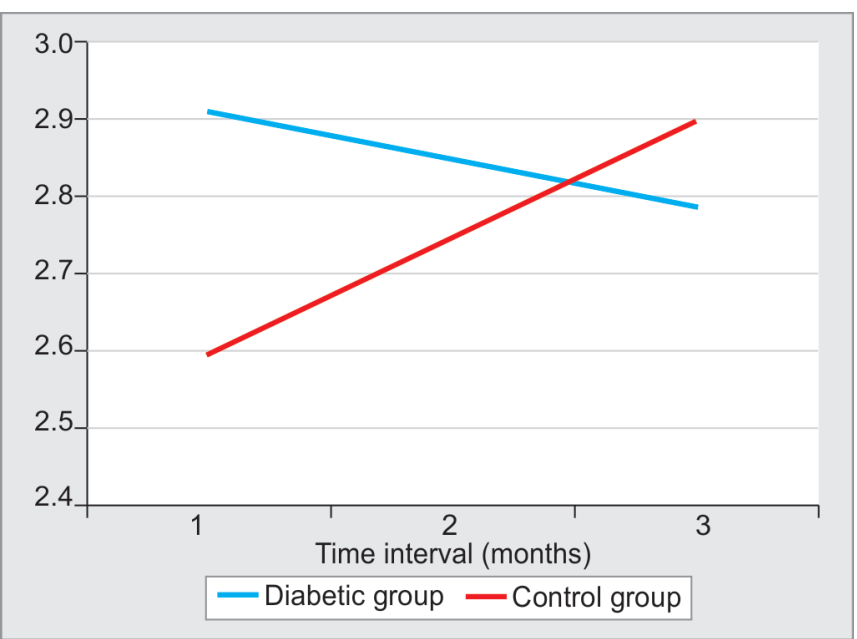

Graph 2: Mean levels of OP (log $10 \mathrm{pg} / \mathrm{mL})$ during follow-up time 


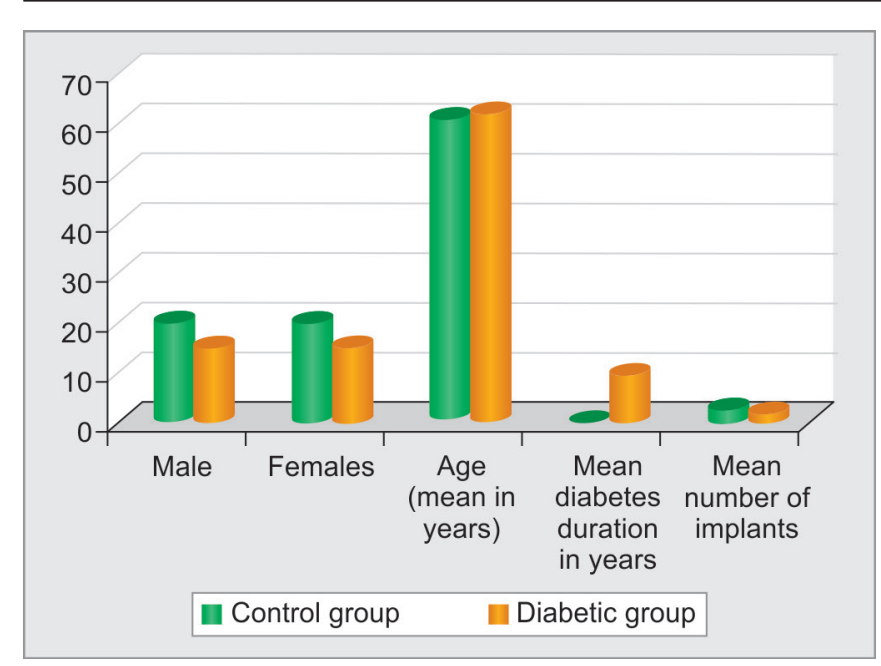

Graph 3: Demographic details of the patients

Mean age of the patients in diabetic and control group were 62 and 61 years respectively. Table 1 shows the clinicoradiographic parameters of teeth and implants. Significant alteration was obtained while comparing the mean PPD, mean $\mathrm{AL}$, mean $\mathrm{BP}$, and mean plaque index values between the two study groups. Table 2 shows the qualitative assessment of the predominant microbial flora in the two study groups. No significant correlation was obtained while comparing the microbial flora of diabetic and control group.

\section{DISCUSSION}

Number of diabetic patients, in the recent Indian and Chinese studies, has surpassed the estimated figures given by the International Diabetes Foundation in 2009. ${ }^{6,7}$ Dental implants have become increasingly popular over the last few decades because of the comfort provided by them in comparison to the fixed partial dentures and removable partial dentures. ${ }^{8-11}$ One of the reasons that has popularized dental implant treatment in the present world's scenario is the growing economy of the developing countries. Diabetes is one of the commonly observed conditions affecting major proportion of the world. Problems may be

Table 1: Clinicoradiographic parameters at teeth and implants

\begin{tabular}{|c|c|c|c|c|c|}
\hline \multirow[b]{2}{*}{ Variable } & \multirow[b]{2}{*}{ Groups } & \multicolumn{2}{|c|}{ Dental implant } & \multicolumn{2}{|c|}{ Teeth } \\
\hline & & Baseline time & 1 year & Baseline time & 1 year \\
\hline \multirow[t]{2}{*}{ Mean PPD (mm) } & Control & $2.03^{* *}$ & $2.21^{* *}$ & 1.60 & 1.55 \\
\hline & Diabetic & $1.96^{* *}$ & $2.36^{*, * *}$ & 1.64 & 1.57 \\
\hline \multirow[t]{2}{*}{ Mean AL (mm) } & Control & $0.64^{* *}$ & $0.58^{\star * *}$ & 1.40 & 1.47 \\
\hline & Diabetic & $0.62^{* *}$ & $0.68^{* *}$ & 1.59 & 1.68 \\
\hline \multirow[t]{2}{*}{ Mean BP (0/1) } & Control & $0.63^{* *}$ & $0.57^{* *}$ & 0.34 & 0.31 \\
\hline & Diabetic & $0.53^{* *}$ & $0.69^{* *}$ & 0.26 & 0.27 \\
\hline \multirow[t]{2}{*}{ Mean plaque index $(0 / 1)$} & Control & 0.22 & 0.14 & 0.25 & 0.22 \\
\hline & Diabetic & $0.12^{* *}$ & 0.15 & 0.31 & 0.31 \\
\hline \multirow[t]{2}{*}{ Mean radiological bone level $(\mathrm{mm})$} & Control & 2.64 & 2.55 & 2.73 & $2.78^{*}$ \\
\hline & Diabetic & 2.52 & 2.71 & 2.61 & $2.67^{*}$ \\
\hline
\end{tabular}

*Significant difference in intragroup over follow-up time; **significant difference between the two study groups at the same follow-up time; ${ }^{* * *}$ significant difference between the two groups when compared overall

Table 2: Predominant pathogenic flora identified at teeth and implants in all the patients

\begin{tabular}{|c|c|c|c|c|c|}
\hline \multirow[b]{2}{*}{ Species } & \multirow[b]{2}{*}{ Groups } & \multicolumn{2}{|c|}{ Dental implant } & \multicolumn{2}{|c|}{ Teeth } \\
\hline & & Baseline time & 1 year & Baseline time & 1 year \\
\hline \multirow[t]{2}{*}{ Tannerella forsythia (\%) } & Control & 1.58 & 1.64 & 1.25 & 2.00 \\
\hline & Diabetic & 1.64 & 1.62 & 1.26 & 1.26 \\
\hline \multirow[t]{2}{*}{ Treponema denticola (\%) } & Control & 0.47 & 0.80 & $0.72^{*}$ & $0.74^{* *}$ \\
\hline & Diabetic & 0.48 & 0.56 & 0.45 & 0.65 \\
\hline \multirow[t]{2}{*}{ Porphyromonas gingivalis (\%) } & Control & 0.82 & 0.99 & 0.90 & 0.84 \\
\hline & Diabetic & 0.58 & 0.78 & 0.78 & 0.89 \\
\hline \multirow[t]{2}{*}{ Fusobacterium nucleatum (\%) } & Control & 2.34 & 2.47 & 2.22 & 2.18 \\
\hline & Diabetic & 2.27 & 2.05 & 2.13 & 2.44 \\
\hline \multirow[t]{2}{*}{ Prevotella intermedia (\%) } & Control & 1.67 & 1.88 & 1.88 & 1.55 \\
\hline & Diabetic & 1.52 & 1.56 & 1.32 & 1.68 \\
\hline \multirow[t]{2}{*}{ Aggregatibacter actinomycetemcomitans (\%) } & Control & 1.66 & 1.72 & 1.65 & 1.77 \\
\hline & Diabetic & 1.34 & 1.39 & 1.41 & 1.79 \\
\hline \multirow[t]{2}{*}{ Candida albicans (\%) } & Control & 1.65 & 1.81 & 1.70 & 1.75 \\
\hline & Diabetic & 1.54 & 1.71 & 1.61 & 1.74 \\
\hline
\end{tabular}

*Significant difference between the study groups at baseline time of follow-up; ** significant difference between the study groups at 1 year time of follow-up 
encountered by the clinician while planning dental implant surgeries in diabetic patients. ${ }^{12}$ Hence, we assessed the clinicomicrobial and salivary profile of diabetic patients undergoing rehabilitation by dental implants.

While evaluating the mean levels of IL- $\beta$ during follow-up time, no significant correlation was obtained between the control group and diabetic group $(p>0.05)$ (Graph 1). Significant reduction in the mean values of OP was seen between the baseline time and the follow-up time between the control group and the diabetic group $(p<0.05)$ (Graph 2). Similar results were reported in the studies of Costa et al ${ }^{13}$ and $\mathrm{O}^{\prime}$ Sullivan et al. ${ }^{14}$ World Health Organization (WHO) reported similar findings in their studies. For the prevention of further vascular destruction by mediators of inflammation, Schoppet et $\mathrm{al}^{15}$ hypothesized that vascular system releases OP as a part of the compensatory mechanism. Mean AL loss seen in our study was comparable to the results seen in previous studies by Schätzle et al. ${ }^{16}$ As far as radiographic changes are concerned, similar results have been obtained, which correlate with the results of past studies. ${ }^{17}$ No significant differences were observed in the pattern and quantitative analysis of microbial flora in the two study groups. These results collaborated with the previous results of Yuan et al. ${ }^{18}$ Moreover, WHO also reported similar findings. Feloutzis et $\mathrm{al}^{19}$ evaluated osseointegrated international team for implantology [ITI(R)] dental implants to investigate the association of specific IL-1 gene polymorphisms and peri-implant bone loss. They evaluated 90 consecutive Caucasian patients who were treated with minimum of a single ITI implant and observed that more than $30 \%$ of them were positive for IL-1. From the results, they concluded that a higher risk of peri-implant bone loss is associated with heavy smoking. Annibali et $\mathrm{al}^{20}$ evaluated the 1 year survival of dental implants in diabetic patients. They conducted an electronic search of the Cochrane Oral Health Group's Trials Register, Medline, and EMBASE for assessing the survival rate of dental implants in patients suffering from diabetes. They observed a mean cumulative survival rate of around 0.96 before loading of dental implant, while after 1 year follow-up, it was found to be 0.91 . From the results, they concluded that an increasing trend of dental implant failure is observed in diabetic patients during the first year of loading of dental implants. Al Amri et $\mathrm{al}^{21}$ compared the clinicoradiographic variables around short length and long length dental implants in patients with and without diabetes. They evaluated a total of 47 patients who underwent dental implant therapy in mandibular posterior regions. They divided all the patients broadly into two groups. One group included patients with diabetes and other without diabetes. They observed no statistically significant difference in probing depth, bleeding on probing, and other clinical parameters in patients in the two study groups. From the results, they concluded that similar clinicoradiographic stability is exhibited by short implants in comparison to long implants. Shi et $\mathrm{al}^{22}$ assessed whether dental implant failure rate differed in diabetic patients and in patients with controlled diabetes. They made a PubMed, the Cochrane Library, and Clinical Trials.gov search and evaluated those studies which highlighted the failure of dental implant in diabetic patients. They observed no direct association between glycemic levels of the patients and failure rate of dental implants. From the results, they conclude that in patients with controlled and uncontrolled diabetes, no significant difference exists. Nobre Mde $\mathrm{et}^{\mathrm{al}^{23}}$ investigated the prognosis of immediate function of dental implant rehabilitation in diabetic patients with a history of any cardiovascular disease. They retrospectively analyzed 70 diabetic patients in which a total of 352 dental implants were placed. They observed a survival rate of more than $95 \%$, which resulted in a nonsignificant alteration between the patients with and without diabetes. From the results, they concluded that presence or absence of cardiovascular diseases has no effect on survival of dental implants. DeLuca and Zarb ${ }^{24}$ evaluated the effect of cigarette smoking on the failure and survival of dental implants and peri-implant bone loss. They evaluated a total of 235 patients in which a total of 767 Brånemark implants of dental implants were placed. They observed a positive correlation between smoking and peri-implant bone loss. From the results, they concluded that in patients undergoing dental implants and having a long-term history of cigarette smoking should be made aware of consequences and effect of smoking on the desorption of bone around the peri-implant area. Conte et $\mathrm{al}^{25}$ assessed the effect of diabetes on the bone-related gene expression in the areas receiving dental implants. They evaluated a total of 54 patients and observed a low quantity of bone sialoprotein, type I collagen in patients with poorly controlled diabetes.

\section{CONCLUSION}

Authors concluded that similar microbial, salivary marker, and clinicoradiological patterns are seen in nondiabetic patients and in diabetic patients who have maintained their metabolic activities. Further studies on a longer scale need to be conducted for establishing certain concrete guidelines in this field.

\section{REFERENCES}

1. Moraschini V, Poubel LA, Ferreira VF, Barboza Edos S. Evaluation of survival and success rates of dental implants reported in longitudinal studies with a follow-up period of at least 10 years: a systematic review. Int J Oral Maxillofac Surg 2015 Mar;44(3):377-388. 
2. Khader YS, Dauod AS, El-Qaderi SS, Alkafajei A, Batayha WQ. Periodontal status of diabetics compared with nondiabetics: a meta-analysis. J Diabetes Complications 2006 Jan-Feb;20(1): 59-68.

3. Abiko Y, Selimovic D. The mechanism of protracted wound healing on oral mucosa in diabetes. Review. Bosn J Basic Med Sci 2010 Aug;10(3):186-191.

4. Haffajee AD, Socransky SS, Goodson JM. Comparison of different data analyses for detecting changes in attachment level. J Clin Periodontol 1983 May;10(3):298-310.

5. Mullally BH, Dace B, Shelburne CE, Wolff LF, Coulter WA. Prevalence of periodontal pathogens in localized and generalized forms of early-onset periodontitis. J Periodontal Res 2000 Aug;35(4):232-241.

6. Yang W, Lu J, Weng J, Jia W, Ji L, Xiao J, Shan Z, Liu J, Tian H, Ji Q, et al. Prevalence of diabetes among men and women in China. N Engl J Med 2010 Mar;362(12):1090-1101.

7. Vaz NC, Ferreira AM, Kulkarni MS, Vaz FS. Prevalence of diabetes mellitus in a rural population of Goa, India. Natl Med J India 2011 Jan-Feb;24(1):16-18.

8. International Diabetes Federation. Diabetes atlas. 4th ed. Montreal, Canada: International Diabetes Federation; 2009.

9. Machtei EE, Frankenthal S, Blumenfeld I, Gutmacher Z, Horwitz J. Dental implants for immediate fixed restoration of partially edentulous patients: a 1-year prospective pilot clinical trial in periodontally susceptible patients. J Periodontol 2007 Jul;78(7):1188-1194.

10. Levin L, Sadet P, Grossmann Y. A retrospective evaluation of 1,387 single-tooth implants: a 6-year follow-up. J Periodontol 2006 Dec;77(12):2080-2083.

11. Levin L, Nitzan D, Schwartz-Arad D. Success of dental implants placed in intraoral block bone grafts. J Periodontol 2007 Jan;78(1):18-21.

12. Heath H, Lambert PW, Service FJ, Arnaud SB. Calcium homeostasis in diabetes mellitus. J Clin Endocrinol Metab 1979 Sep;49(3):462-466.

13. Costa FO, Takenaka-Martinez S, Cota LO, Ferreira SD, Silva GL, Costa JE. Peri-implant disease in subjects with and without preventive maintenance: a 5-year follow-up. J Clin Periodontol 2012 Feb;39(2):173-181.

14. O'Sullivan EP, Ashley DT, Davenport C, Devlin N, Crowley R, Agha A, Thompson CJ, O'Gorman D, Smith D. Osteoprotegerin and biomarkers of vascular inflammation in type 2 diabetes. Diabetes Metab Res Rev 2010 Sep;26(6):496-502.

15. Schoppet M, Sattler AM, Schaefer JR, Herzum M, Maisch B, Hofbauer LC. Increased osteoprotegerin serum levels in men with coronary artery disease. J Clin Endocrinol Metab 2003 Mar;88(3):1024-1028.

16. Schätzle M, Löe H, Lang NP, Heitz-Mayfield LJ, Bürgin W, Anerud A, Boysen H. Clinical course of chronic periodontitis. III. Patterns, variations and risks of attachment loss. J Clin Periodontol 2003 Oct;30(10):909-918.

17. Paulander J, Axelsson P, Lindhe J, Wennström JL. Intra-oral pattern of tooth and periodontal bone loss between the age of 50 and 60 years. A longitudinal prospective study. Acta Odontol Scand 2004 Aug;62(4):214-222.

18. Yuan K, Chang CJ, Hsu PC, Sun HS, Tseng CC, Wang JR. Detection of putative periodontal pathogens in noninsulin-dependent diabetes mellitus and non-diabetes mellitus by polymerase chain reaction. J Periodontal Res 2001 Feb;36(1):18-24.

19. Feloutzis A, Lang NP, Tonetti MS, Bürgin W, Brägger U, Buser D, Duff GW, Kornman KS. IL-1 gene polymorphism and smoking as risk factors for peri-implant bone loss in a well-maintained population. Clin Oral Implants Res 2003 Feb;14(1):10-17.

20. Annibali S, Pranno N, Cristalli MP, La Monaca G, Polimeni A. Survival analysis of implant in patients with diabetes mellitus: a systematic review. Implant Dent 2016 Oct;25(5): 663-674.

21. Al Amri MD, Abduljabbar TS, Al-Johany SS, Al Rifaiy MQ, Alfarraj Aldosari AM, Al-Kheraif AA. Comparison of clinical and radiographic parameters around short (6 to $8 \mathrm{~mm}$ in length) and long (11 $\mathrm{mm}$ in length) dental implants placed in patients with and without type 2 diabetes mellitus: 3-year follow-up results. Clin Oral Implants Res 2016 Jul 29. doi: 10.1111/clr.12938. [Epub ahead of print]

22. Shi Q, Xu J, Huo N, Cai C, Liu H. Does a higher glycemic level lead to a higher rate of dental implant failure? A meta-analysis. J Am Dent Assoc 2016 Nov;147(11):875-881.

23. Nobre Mde A, Maló P, Gonçalves Y, Sabas A, Salvado F. Outcome of dental implants in diabetic patients with and without cardiovascular disease: a 5-year post-loading retrospective study. Eur J Oral Implantol 2016 Spring;9(1): 87-95.

24. DeLuca S, Zarb G. The effect of smoking on osseointegrated dental implants. Part II: peri-implant bone loss. Int J Prosthodont 2006 Nov-Dec;19(6):560-566.

25. Conte A, Ghiraldini B, Casarin RC, Casati MZ, Pimentel SP, Cirano FR, Duarte PM, Ribeiro FV. Impact of type 2 diabetes on the gene expression of bone-related factors at sites receiving dental implants. Int J Oral Maxillofac Surg 2015 Oct;44(10):1302-1308. 